\title{
Weak solutions in Elasticity of dipolar bodies with stretch
}

\section{MARIN MARIN and GABRIEL STAN}

\section{ABSTRACT.}

In the present paper we generalize the results obtained by Iesan and Quintanilla for microstretch elastic bodies in order to cover the dipolar elastic materials with stretch. For the boundary value problem considered in this context, we use some results from the theory of semigroups of the linear operators in order to prove the existence and uniqueness of a weak solution.
\end{abstract}

\author{
DEPT. OF MATHEMATICS AND INFORMATICS \\ "TRANSILVANIA" UNIVERSITY OF BRASOV \\ IULIU MANIU 50, BRASOV, ROMANIA \\ E-mail address: m.marin@unitbv.ro \\ E-mail address: g. stan@unitbv.ro
}

Received: 08.12.2010; In revised form: 16.10.2012; Accepted: 12.12.2012

2010 Mathematics Subject Classification. 73B30, 73C35, 73C60.

Key words and phrases. Elastostatics, dipolar bodies, stretch, semigroup of operators.

Corresponding author: Marin Marin; m.marin@unitbv.ro 